\title{
Investigation of the Impacts of Large-Scale Wind Power Penetration on the Angle and Voltage Stability of Power Systems
}

\author{
M. J. Hossain, Member, IEEE, H. R. Pota, M. A. Mahmud and Rodrigo A. Ramos, Senior Member, IEEE
}

\begin{abstract}
The complexity of power systems has increased in recent years due to the operation of existing transmission lines closer to their limits, using flexible AC transmission system devices (FACTS), and also due to the increased penetration of new types of generators that have more intermittent characteristics and lower inertial response, such as wind generators. This changing nature of a power system has considerable effect on its dynamic behaviours resulting in power swings, dynamic interactions between different power system devices and less synchronized coupling. This paper presents some analyses of this changing nature of power systems and their dynamic behaviours to identify critical issues that limit the large-scale integration of wind generators and FACTS devices. In addition, this paper addresses some general concerns towards high compensations in different grid topologies. The studies in this paper are conducted on the New England and New York power system model under both small and large disturbances. From the analyses, it can be concluded that high compensation can reduce the security limits under certain operating conditions, and the modes related to operating slip and shaft stiffness are critical as they may limit the large-scale integration of wind generation.
\end{abstract}

\section{INTRODUCTION}

Power systems are complex systems that evolve over years in response to economic growth and continuously increasing power demand. With growing populations and the industrialization of the developing world, more energy is required to satisfy basic needs and to attain improved standards of human welfare [1]. The structure of the modern power system is becoming highly complex in order to make energy available economically with reduced carbon emission using renewable energy sources.

In recent years, power demand has increased substantially while the expansion of power transmission lines has been severely limited due to inadequate resources and environmental restrictions. As a consequence, some transmission lines are heavily loaded and the system stability becomes a power transfer-limiting factor. FACTS controllers have been used for solving various power system steady-state control problems, enhancing power system stability in addition to their main function of power flow control [2].

Following the issue of the Renewable Energy Regulation to give impetus to the development of renewable energy by governments in Denmark, Germany, USA, China, Ireland,

\footnotetext{
M. J. Hossain is with Griffith School of Engineering, Griffith University, Gold Coast, QLD-4022, Australia (j.hossainegriffith.edu.au).

M. J. Hossain, H. R. Pota, M. A. Mahmud are with the school of Engineering and Information Technology, UNSW@ADFA, Canberra, ACT2600, Australia (m.hossain, h.pota) eadfa.edu.au.

R. A. Ramos is with the Dept. of Electrical Engg., Engineering School of São Carlos, Brazil (ramos@sel.eese.usp.br) .
}

Australia, India, a large number of wind farms are currently interconnected into the existing transmission network of $220 \mathrm{kV}$ voltage level with higher installed capacity than the connected conventional generation. This increased amount of wind installation has considerable effects on the operation of existing transmission network. The European Wind Energy Association (EWEA) projects $230 \mathrm{GW}$ by 2020 and $300 \mathrm{GW}$ of installed wind power capacity in Europe by 2030. An overview of the historical development of wind energy technology and the current world-wide status of grid-connected as well as stand-alone wind power generation is given in [3]. The present and progressive scale of integration has brought to a head serious concerns about the impact of such a scale of wind penetration on the future safety, stability, reliability and security of the electricity system.

There are several technical constraints, including steadystate or dynamic stability, that may limit wind power integration into a power system. A majority of large wind farms, including proposed large wind projects, are geographically far away from load centers and connected into relatively weak transmission networks [4]. The presence of wind farms in such weak transmission networks incurs serious concerns about system security and stability. Power system utilities concerns are shifting focus from the power quality issues to the stability problems caused by the wind power integration. In the grid impact studies of wind power integration, the voltage stability issue is a key problem because a large proportion of existing wind farms are based on fixed-speed wind turbines (FSWTs) equipped with simple induction generators [5].

Induction generators consume reactive power and behave similar to induction motors during system contingency, which deteriorates the local grid voltage stability [6]. Presently variable speed wind turbines equipped with doubly fed induction generators (DFIG) are becoming more widely used for their advanced reactive power and voltage control capability. DFIGs make use of power electronic converters and are thus able to regulate their own reactive power to operate at a given power factor as well as able to control grid voltage. However, because of the limited capacity of the PWM (pulse-width modulation) converter, the voltage control capability of DFIG cannot catch up with that of the synchronous generator. When the voltage control requirement is beyond the capability of the DFIG, the voltage stability of the grid is also affected.

Recently, a lot of work has been done to analyze the effects of large scale integration of wind generators on dynamic stability. The effect of wind power on the oscillations and damping has been investigated by gradually replacing the power generated by the synchronous generators in the system by power from either constant or variable speed induction generators [7], [8]. Only, the impact on electromechanical 
modes has been investigated in [7], although the voltage modes are also influenced due to penetration of wind generators. The limits for voltage stability at different wind power integration levels and grid alternatives have been illustrated in [9] for situations with and without extra stabilizing controls in the system (SVC) and for different characteristics for the wind turbine generators. Detailed dynamic load modeling and fault analysis are not treated in [9]. However, load characteristics are closely related to voltage instability [10], [11].

The issues of interconnecting large wind parks to the electrical power network are discussed and possible solutions to counteract anticipated problems using AC and DC transmission technologies, and FACTS devices with energy storage are presented in [12]. The impact of grid-connected large DFIG based wind farms on power system transient stability has been studied in detail including full generator model, as there is a lack of this generator model in the most common transient simulation software packages [13]. It is shown in [13] that power system transient stability can be improved to some extent when the specified synchronous generator is replaced by a wind farm of DFIG type. The effect of short circuiting the rotor when the fault current exceeds the converter rating is not considered in this paper [13]. However, during large disturbances, doubly-fed induction generators (DFIG) behave as conventional SCIGs with an increased rotor resistance [14].

The challenge to accommodate increasingly larger amounts of wind energy on the system and its impact on system operation has been discussed in [15]. The challenges with regard to incorporation of dispersed power generation and particularly large offshore wind power into the Danish power system have been discussed in [16]. This article mainly focuses on investigations of short-term voltage stability as one of the main concerns has been to evaluate the response of the power grid to a short-circuit fault in the transmission system. The technical issues to integrate large wind power into weak grids with long transmission lines and the most significant challenges for wind generation facilities, including voltage control, reactive power management, dynamic power-swing stability, and behavior following disturbances in the power grid have been addressed in [17]. It is shown in [17] that the decoupled characteristics of variable wind power plants with the grids ensure stability performance which can exceed that of conventional synchronous generations of the same rating, installed at the same locations.

Although much work has been done, the following issues have not been addressed in detail yet: (i) effects of importing higher level of power from remote generation with high penetration of FACTS devices; (ii) effects of high penetration of DFIGs on voltage stability during transients when they behave as SCIGs; (iii) the critical interaction between FACTS devices; and (iv) effects of the integration of FSWTs and FACTS device with substantial amounts of dynamic load. Large wind generation facilities are evolving to look more and more like conventional generating plants in terms of their ability to interact with the transmission network and other generating units and FACTS devices in a way that does not compromise performance or system reliability. But many challenges and new breakthroughs are needed before it becomes a reality.
The effect of load changing transformers and induction motor loads on voltage stability has been detailed in [18] on voltage stability. In this paper, attention is focused on the reactive power compensation and induction generation. The novelty of the present work is to show that (a) over compensation for reactive power can lead to dynamic instability with a strong coupling between voltage and angle dynamics, and (b) turbines and induction generators introduces mechanical modes which should be considered for high wind energy penetration. One obvious conclusion from this work is that with wind energy penetration dynamic reactive power compensation, voltage and angle dynamics have a stronger interaction compared to the systems with synchronous generation and static VAR compensation.

The other purpose of this paper to analyze the changing nature of systems and its dynamic behavior to identify future issues that either resolving or defining limits to the degree that can be tolerated. So far in the literature, the following cases are not considered: (i) the possible effects of higher FACTS density on dynamic performance of distributed power systems, (ii) the critical interaction amongst FACTS devices, (iii) whether there is a level of wind generation capacity and FACTS devices above which the system dynamic behavior is unstable with poor controllability. This paper will address the these issues.

The organization of the paper is as follows: Section II describes the models used to represent the main network components and the electrical system; Section IIIprovides a short description of the test system used in this paper; in Section IV, a number of case studies and discussions are outlined. The conclusions are summarized in Section V.

\section{Power System Model}

Dynamic models of the devices considered in the paper are presented in this section. For stability analysis we include the transformer and the transmission line in the reduced admittance matrix. The nonlinear model of the wind turbines is based on a static model of the aerodynamics, a two mass model of the drive train, and a third order model of the induction generator.

The rotor of the wind turbine, with radius $R_{i}$, converts energy from the wind to the rotor shaft, rotating at the speed, $\omega_{m_{i}}$. The power from the wind depends on the wind speed, $V_{w_{i}}$, the air density, $\rho_{i}$, and the swept area, $A_{w t_{i}}$. From the available power in the swept area, the power on the rotor is given based on the power coefficient $c_{p_{i}}\left(\lambda_{i}, \theta_{i}\right)$, which depends on the pitch angle of the blade, $\theta_{i}$, and the ratio between the speed of the blade tip and the wind speed, denoted tip-speed ratio, $\lambda_{i}=\frac{\omega_{m_{i}} R_{i}}{V_{w_{i}}}$. The aerodynamic torque applied to the rotor for the $i^{\text {th }}$ turbine by the effective wind speed passing through the rotor is given as [19]:

$$
T_{a e_{i}}=\frac{\rho_{i}}{2 \omega_{m_{i}}} A_{w t_{i}} c_{p_{i}}\left(\lambda_{i}, \theta_{i}\right) V_{w_{i}}^{3}
$$

where $c_{p_{i}}$ is approximated by the following relation [20]:

$c_{p_{i}}=\left(0.44-0.0167 \theta_{i}\right) \sin \left[\frac{\pi\left(\lambda_{i}-3\right)}{15-0.3 \theta_{i}}\right]-0.00184\left(\lambda_{i}-3\right) \theta_{i}$, 
where $i=1, \cdots, n$, and $n$ is the number of wind turbines.

The drive train attached to the wind turbine converts the aerodynamic torque $T_{a e_{i}}$ on the rotor into the torque on the low speed shaft, which is scaled down through the gearbox to the torque on the high-speed shaft. A two-mass drive train model of a wind turbine generator system (WTGS) is used in this paper as the drive train modeling can satisfactorily reproduce the dynamic characteristics of the WTGS. The first inertia constants, $H_{m_{i}}$ stands for the blades, hub and low-speed shaft, while the second inertia constants, $H_{G_{i}}$ stands for the high-speed shaft. The shafts are interconnected by a gear box with a gear ratio, $N_{g_{i}}$, combined with torsion stiffness, $K_{s_{i}}$, and torsion damping, $D_{m_{i}}$ and $D_{G_{i}}$, resulting in torsion angle $\gamma_{i}$. The normal grid frequency is $f$. The dynamics of the shaft are represented as [19]:

$$
\begin{aligned}
\dot{\omega}_{m_{i}} & =\frac{1}{2 H_{m_{i}}}\left[T_{a e_{i}}-K_{s_{i}} \gamma_{i}-D_{m_{i}} \omega_{m_{i}}\right], \\
\dot{\omega}_{G_{i}} & =\frac{1}{2 H_{G_{i}}}\left[K_{s_{i}} \gamma_{i}-T_{e_{i}}-D_{G_{i}} \omega_{G_{i}}\right], \\
\dot{\gamma}_{i} & =2 \pi f\left(\omega_{m_{i}}-\frac{1}{N_{g_{i}}} \omega_{G_{i}}\right) .
\end{aligned}
$$

The generator gets the mechanical power from the gear box through the stiff shaft. The relationship between the mechanical torque and the torsional angle is given by:

$$
T_{m i}=K_{s_{i}} \gamma_{i}
$$

For representation of fixed-speed induction generator models in power system stability studies, the stator flux transients can be neglected in the voltage relations [21]. A simplified transient model of a single cage induction generator (IG) with the stator transients neglected and rotor currents eliminated is described by the following algebraic-differential equations [19], [21]:

$$
\begin{aligned}
& \dot{s}_{i}=\frac{1}{2 H_{G_{i}}}\left[T_{m_{i}}-T_{e_{i}}\right], \\
& \dot{E}_{q r_{i}}^{\prime}=-\frac{1}{T_{o_{i}}^{\prime}}\left[E_{q r_{i}}^{\prime}-\left(X_{i}-X_{i}^{\prime}\right) i_{d s_{i}}\right]-s_{i} \omega_{s} E_{d r_{i}}^{\prime}, \\
& \dot{E}_{d r_{i}}^{\prime}=-\frac{1}{T_{o_{i}}^{\prime}}\left[E_{d r_{i}}^{\prime}+\left(X_{i}-X_{i}^{\prime}\right) i_{q s_{i}}\right]+s_{i} \omega_{s} E_{q r_{i}}^{\prime}, \\
& V_{d s_{i}}=R_{s_{i}} i_{d s_{i}}-X_{i}^{\prime} i_{q s_{i}}+E_{d r_{i}}^{\prime}, \\
& V_{q s_{i}}=R_{s_{i}} i_{d s_{i}}+X_{i}^{\prime} i_{q s_{i}}+E_{q r_{i}}^{\prime}, \\
& v_{t_{i}}=\sqrt{V_{d s_{i}}^{2}+V_{q s_{i}}^{2}},
\end{aligned}
$$

where $X_{i}^{\prime}=X_{s_{i}}+X_{m_{i}} X_{r_{i}} /\left(X_{m_{i}}+X_{r_{i}}\right)$, is the transient reactance, $X_{i}=X_{s_{i}}+X_{m_{i}}$, is the rotor open-circuit reactance, $T_{o_{i}}^{\prime}=\left(L_{r_{i}}+\right.$ $\left.L_{m_{i}}\right) / R_{r_{i}}$, is the transient open-circuit time constant, $v_{t_{i}}$ is the terminal voltage of the IG, $s_{i}$ is the slip, $E_{d r_{i}}^{\prime}$ is the directaxis transient voltages, $E_{q r_{i}}^{\prime}$ is the quadrature-axis transient voltages, $V_{d s_{i}}$ is the d-axis stator voltage, $V_{q s_{i}}$ is the q-axis stator voltage, $T_{m_{i}}$ is the mechanical torque, $T_{e_{i}}=E_{d r_{i}} i_{d s_{i}}+$ $E_{q r_{i}} i_{q s_{i}}$, is the electrical torque, $X_{s_{i}}$ is the stator reactance, $X_{r_{i}}$ is the rotor reactance, $X_{m_{i}}$ is the magnetizing reactance, $R_{S_{i}}$ is the stator resistance, $R_{r_{i}}$ is the rotor resistance, $H_{G_{i}}$ is the inertia constant of the $\mathrm{IG}, \delta_{i}=\int_{0}^{t} \omega_{G_{i}} d t$, is the rotor angle,
$\omega_{G_{i}}$ is the rotor speed of the IG, $\omega_{s}$ is the synchronous speed, $i_{d s_{i}}$ and $i_{q s_{i}}$ are d-and q-axis components of the stator current, respectively.

All the generators of the test system $\left(G_{1}\right.$ to $\left.G_{16}\right)$ have been represented by a sub-transient model [22]. The mechanical input power to the generators is assumed to be constant during the disturbance. The generators $G_{1}$ to $G_{8}$ are equipped with slow excitation system (IEEE-DC1A) whilst $G_{9}$ is equipped with a fast acting static excitation system (IEEE-ST1A) [22]. The fast acting static excitation system at generator $G_{9}$ is equipped with a power system stabilizer to provide supplementary damping control for the local modes. The rest of the generators are under manual excitation control [22]. The load is modeled as (i) $20 \%$ large induction motor load [10], (ii) $25 \%$ small induction motor load [10], and (iii) $45 \%$ static load. The active components of static loads were represented by constant current models and the reactive components by constant impedance models, as recommended in [23] for dynamic simulations.

In this paper, fixed-speed induction generators and DFIGs have been considered for the analysis. The modeling of induction generators for power flow and dynamic analysis has been discussed in [19], [21]. A general model for representation of variables speed wind turbines in power system dynamics simulations has been presented in [24]. A TCSC [22], SVC [22] and STATCOM [6] have been used in this paper.

\section{TEST SYSTEM}

A 16 machine, 69 bus system is considered in this paper [22]. The single line diagram of the system is shown in Fig.1. This is reduced order equivalent of the interconnected New England test system (NETS) and New York power system (NYPS). There are five geographical regions, out of which NETS and NYPS are represented by a group of generators whereas, import from each of the three other neighboring areas 3,4 and 5 are approximated by generator equivalent models. The generators, loads and imports from other neighboring areas are representative of operating conditions in the early 1970s. The total load on the system is $P_{L}=17620.65 \mathrm{MW}$, $Q_{L}=1971.76 \mathrm{MVAr}$ and generation $P_{G}=18408.00 \mathrm{MW}$. The line loss in the system is $152.2 \mathrm{MW}$. Generators $G_{1}$ and $G_{9}$ are the equivalent representation of the NETS generator whilst machines $G_{10}$ to $G_{13}$ represent the generation of the NYPS. Generators $G_{14}$ to $G_{16}$ are the dynamics equivalents of the three neighboring areas connected to the NYPS. There are three major transmission corridors between NETS and NYPS connecting buses 60-61, 53-54 and 27-53. All these corridors have double-circuit tie-lines. In steady state, the tie-line power exchange between NETS and NYPS is $700 \mathrm{MW}$ in total. The NYPS is required to import $1500 \mathrm{MW}$ from area 5. The system and generator data are given in [22].

At the present time, there are at least three main wind turbine technologies used in the industry.

\section{CAse Studies}

A number of cases have been considered to get a deeper insight into these complex issues but a few of them are 


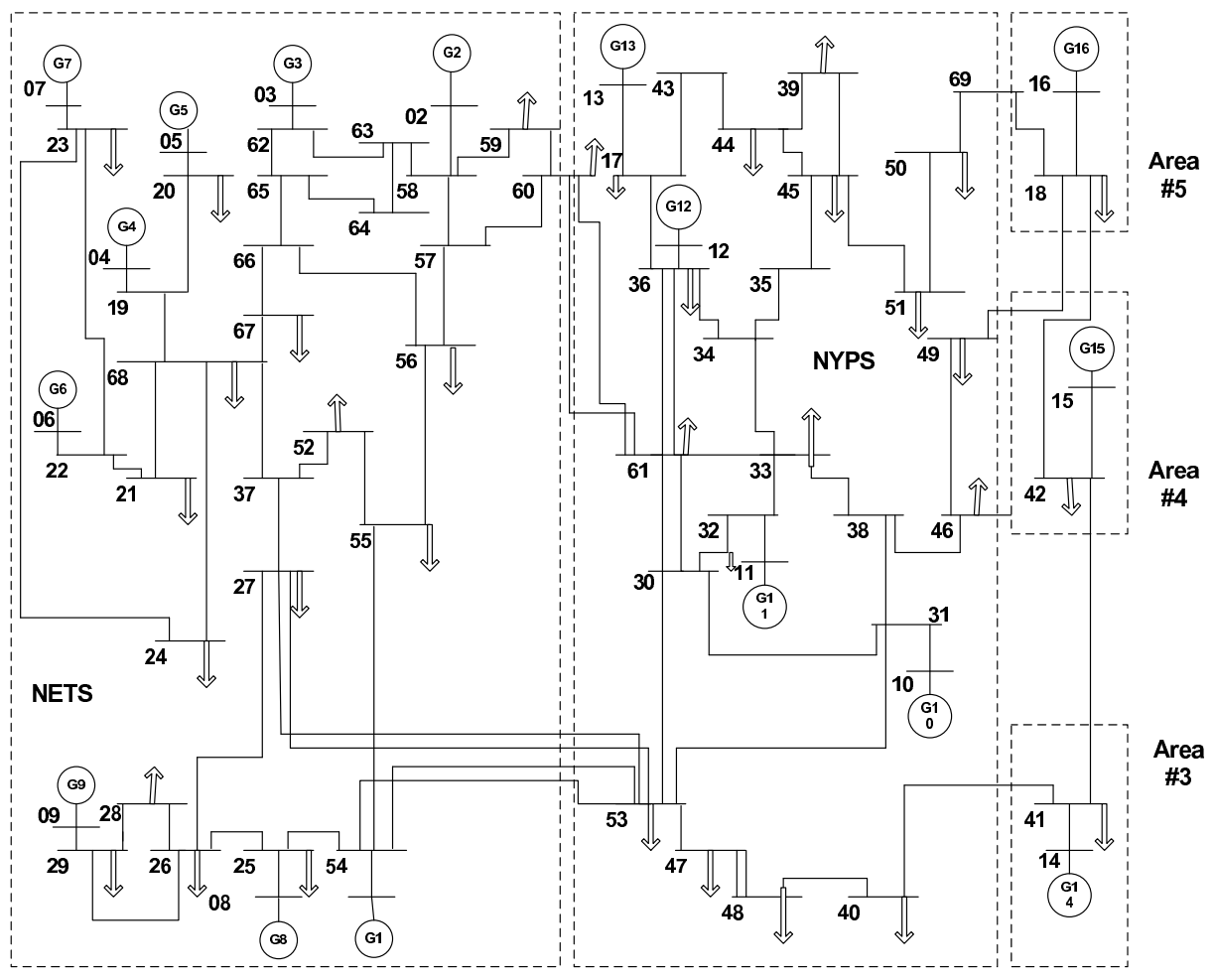

Fig. 1. Test System.

presented in this paper because of space limitation. Simulation studies have been carried out using nonlinear models of different power system devices and widely used power system simulator (PSSE).

\section{A. Load area fed by high import using high compensation}

A large amount of compensation is needed within the load area. This is caused by the high demand for reactive power by the loads, the need for a lot of reactive power of the feeding lines and the lack of generation units within the load area that could deliver reactive power as a by-product. A large amount of reactive compensation results in a PV curve that is flat to a certain point. From there, it falls very steeply. The effect is, that the voltages are on a good level for a long time and nobody sees a problem. But the security margin of voltage instability is very small in reality and a small event can pull the system down.

Both the P-V curve method [25] and nonlinear simulations [18] are used to analyze this issue. The PV curve for bus 49 at area NYPS is shown in Fig. 2 which is highly compensated (750 MVAr) and the load ( $\mathrm{P}=1350 \mathrm{MW}$ and $\mathrm{Q}=29 \mathrm{MVAr}$ ) is supplied from NETS. The system is operated with 864 MW load at bus 49 and voltage remains constant for this loaded condition. A three phase fault is applied at the middle of one of the lines 60-61 and the resulting voltage at bus 49 is shown in Fig. 3. From Fig. 3, it is clear that although the system is highly compensated and operated at constant voltage, instability occurs due to small security margin.

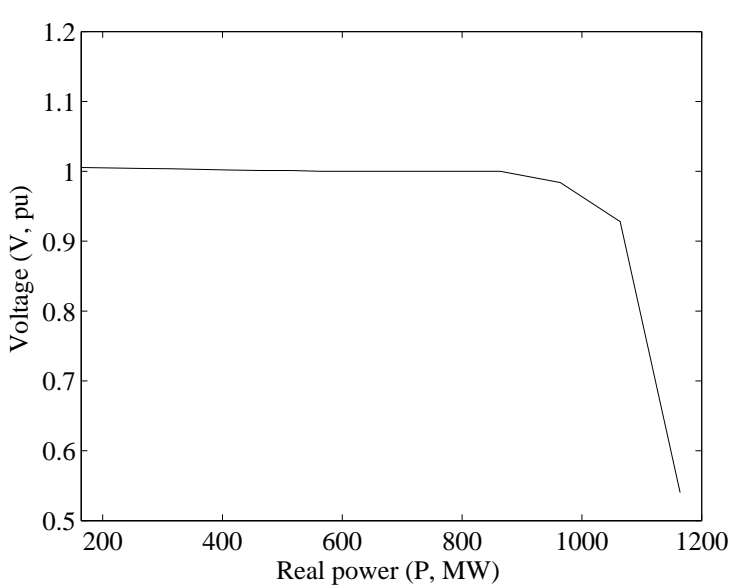

Fig. 2. P-V relationship at bus 49

\section{B. Interaction among different FACTS devices}

Interaction amongst the FACTS devices in a multi-machine system can adversely influence the damping properties of individual FACTS devices. In some critical cases, it may even amplify power swings or increase voltage deviations. Due to local, uncoordinated control strategies used in many power systems, destabilizing interactions among FACTS controls are possible. This problem may occur especially after the clearance of a critical fault, if shunt and series connected devices, e.g., SVC or STATCOM and TCSC, are applied in the same area. Interactions among FACTS controls can adversely influence the rotor damping of generators and under weakly interconnected system conditions it can even cause 


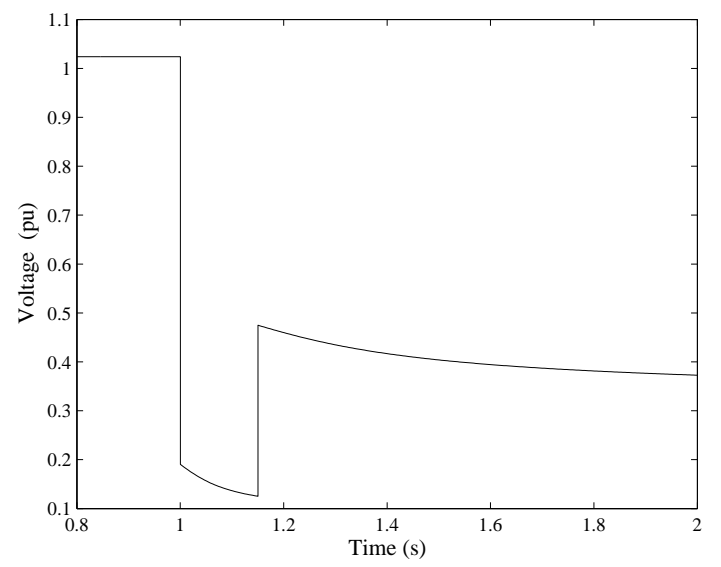

Fig. 3. Voltage at bus 49 for three-phase fault on middle of one of lines 60-61

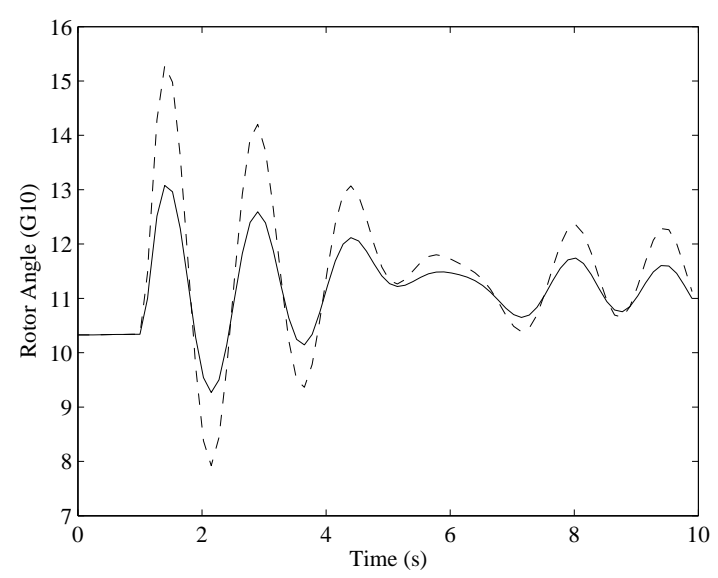

Fig. 4. Rotor angle $G_{10}$ for three-phase fault on middle of one of lines 60-61 (Solid line STATCOM and dashed line STATCOM+TCSC+MSC)

dynamic instability and restrict the operating power range of the generators.

Simulations are conducted with (i) a STATCOM at bus 31 and (ii) a STATCOM at bus 31, an MSC at bus 53 and a TCSC at the middle of the line 30-31. Fig. 4 shows the rotor angle with three phase fault on the middle of one of the lines 60-61. It is clear that the addition of TCSC and MSC nearest to STATCOM increases the rotor angle oscillations. To improve overall system dynamic performance, interactions among FACTS controls must be minimized or prevented.

\section{A few bulk transmission lines with series compensations}

Series compensation can be optimised so that the electrical length of the lines can be reduced. If the compensation is equipped with thyristor control, it can even be used for the damping of power swings. Case studies are carried out for: (i) a base case power flow (200 MW) through one of the lines 60-61; and (ii) an extra power flow with a TCSC of 380 MW (almost double) through the same line. Fig. 5 shows the power flow through the line 60-61(2) for both cases which

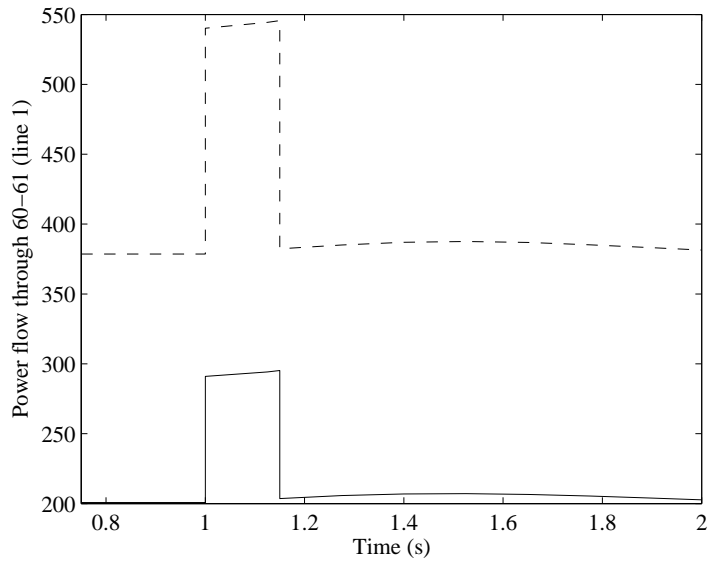

Fig. 5. Power flow (lines 60-61(2)) for outage of one of transmission lines 60-61 (Solid line base case power flow and dashed line extra power flow with TCSC)

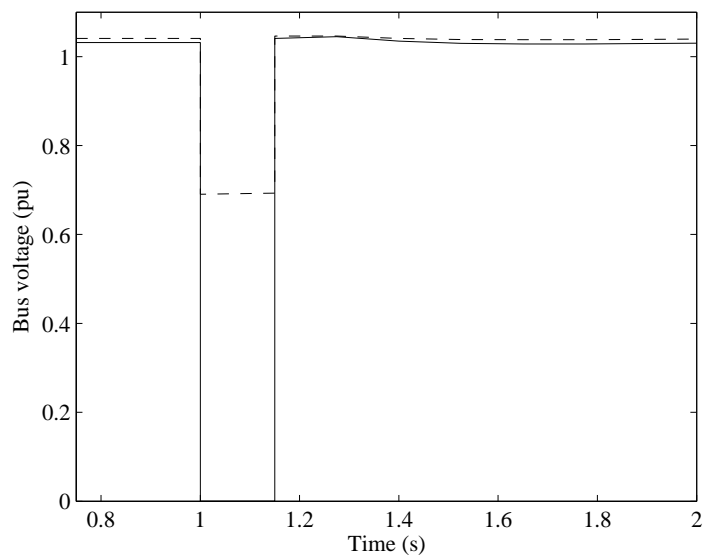

Fig. 6. Voltages at buses 60 and 61 for three-phase fault on middle of one of lines 60-61 (Solid line bus 60 and dashed line 61)

raise no concerns regarding that configuration. The series compensation makes a stable transmission possible.

\section{Longitudinal system with shunt compensation at middle}

If the distances are not too great, line reactive power requirement can be met by compensation at the middle of the system which minimises the distances from the compensation device to the nodes of the system. For this case, a STATCOM is placed at the middle of one the of lines 60-61. Fig. 6 shows the voltage profiles at buses 60 and 61 for a three-phase fault at one of the lines for $150 \mathrm{~ms}$. From Fig. 6, it is evident that the post-fault voltage remains in good condition at both buses.

\section{E. Classical generation close to load centres}

When generators are close to the load centre, only a small amount of compensation is required because the reactive power needed by the lines is relatively low and the consumption of reactive power by the loads can be covered by the generators. A synchronous generator offers dynamic compensation of high quality, i.e., in the case of a decreasing 


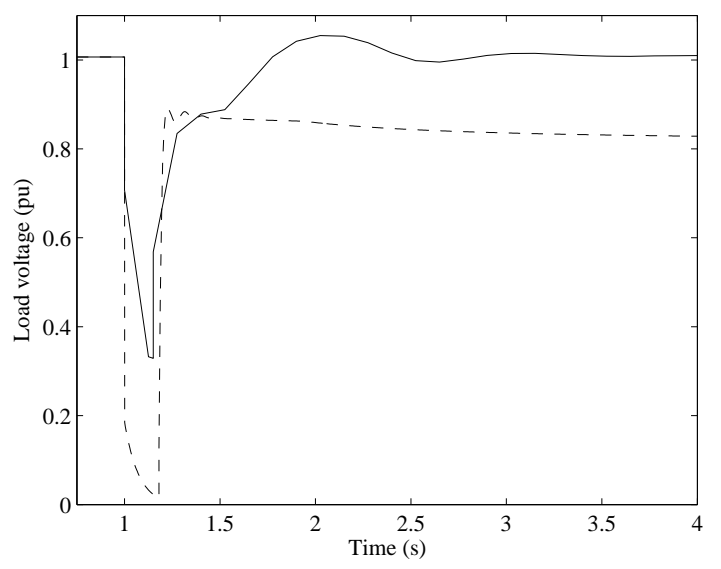

Fig. 7. Voltage at bus 49 for three-phase fault at middle of one of lines 60-61 (Solid line classical local generator and dashed line far FSWT)

voltage at the connecting point, it does not reduce its output of reactive power. The additional compensation delivers a base compensation in order to create an adequate security margin for the generator action.

A study is conducted by increasing the load by $10 \%$ in the NYPS (New York) which, in the first case, is supplied from local generation. In the next case, the extra load is supplied from a remote area, connecting fixed speed wind turbines in New England area. Fig. 7 shows the voltage at bus 49 for a three phase fault at the middle of one of the lines 60-61. Voltage is not recovered for the last case due to high transmission losses in connecting lines and the different behaviours of wind turbines compared with those of synchronous generators.

\section{F. Comparison of different compensation devices}

A possible way of assessing the 'quality' of a compensation device concerning voltage stability may be that the reactive power output of several devices are not compared at the rated voltage of the devices but at the minimum voltage that is accepted in the grid. It could be the voltage at which power plants trip due to under-voltage (or other under-voltage criteria). In this paper, the reactive power output capability of SVC and STATCOM are compared during low-voltage at grid.

An SVC has constant impedance and its reactive power output decreases in proportion to the square of the voltage. It is an active fast reacting device, if it is not yet at its limit before the fault, it can improve the voltage recovery after fault by activating the reserve. A STATCOM is a constant current source and its reactive power output decreases linearly with the voltage. It is also is an active fast reacting device with limited energy storage. Because it can inject a constant current, it can better improve the voltage recovery after fault.

Fig. 8 shows the bus voltage with a STATCOM and a SVC for a three phase fault on the middle of one of the lines 6061. It is clear that during low voltage the STATCOM provides better response and the lower voltage with the STATCOM is much higher than that of the SVC.

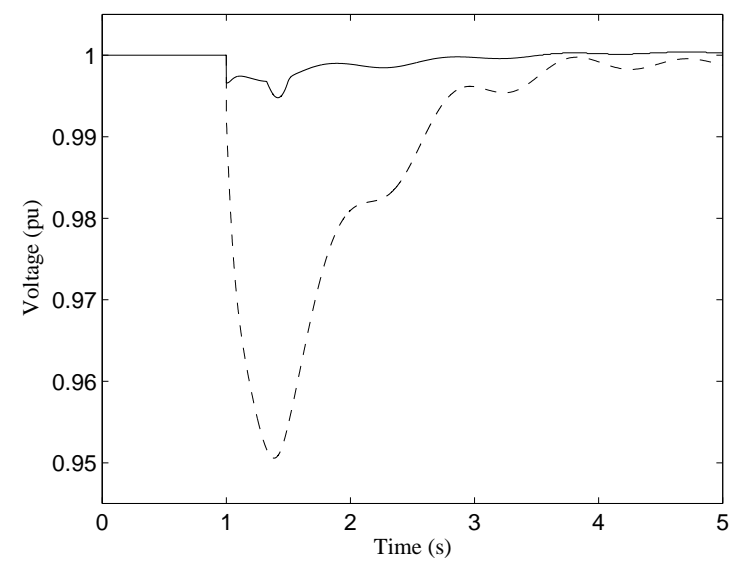

Fig. 8. Voltage at bus 60 for three-phase fault at middle of one of lines 60-61 (Solid line STATCOM and dashed line SVC)

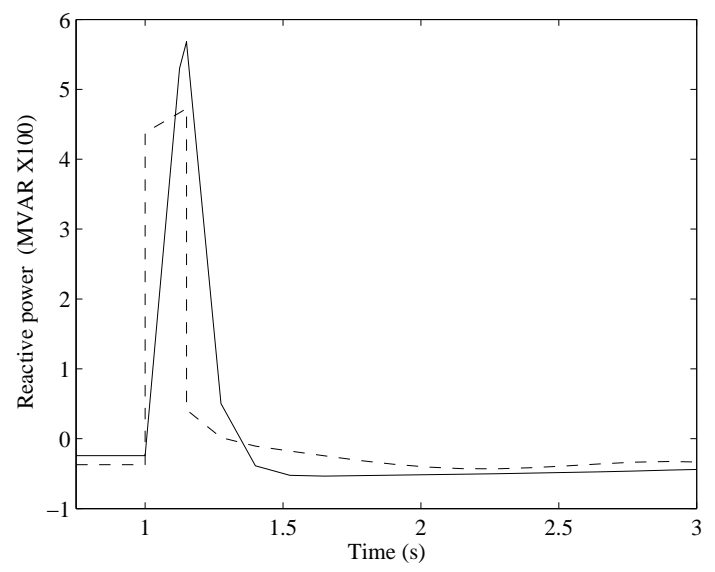

Fig. 9. Reactive Power for three-phase fault at middle of one of lines 60-61 (Solid line generator and dashed line DFIG)

G. Large number of DFIG type wind farms and few synchronous generators

Statically, the DFIGs often do not deliver as much reactive power as synchronous generators do and dynamically they cannot produce the same short circuit current. The post-fault voltage support provided by feeding reactive power is normally worse for DFIG than in the case of a synchronous machine. Although, recent work shows that an improvement in this and voltage support may be possible with DFIG. Due to the inferior behaviour of DFIGs compared to the synchronous generators, a system dominated by DFIGs behaves worse than one with synchronous generation. The effect normally is that more reactive compensation is needed in such systems. During deep voltage sags, the synchronous generator feeds in more reactive current than the DFIG-based wind farm and it thus gives a stronger support to the grid voltage. Also DFIGs consume reactive power when they behave as SCIGs during transients and thus can reduce voltage stability limit.

To analyse this case, (i) the reactive power output of the synchronous generator $\left(G_{10}\right)$ under faulted condition is determined, (ii) this synchronous generator is replaced by the same 


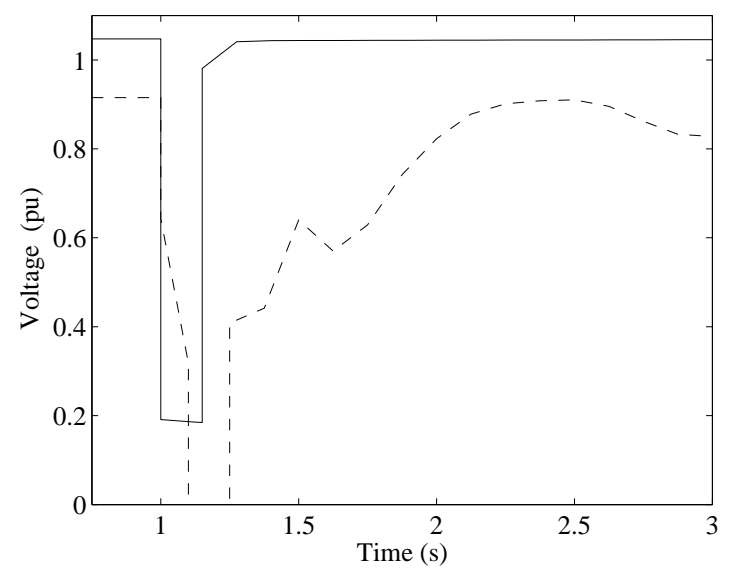

Fig. 10. Voltage at bus 49 for three-phase fault at middle of one of lines 60-61 (Solid line Synchronous generator, and dashed line 60\% DFIGs and $40 \%$ SGs)

capacity DFIG and then its reactive power output is compared to that of the synchronous generator under the same operating conditions. Fig. 9 shows the reactive power supply by the same capacity synchronous generator $\left(G_{10}\right)$ and DFIG during a three phase fault at the middle of line 60-61. Voltage transients for power system with synchronous generators only and a combination of $60 \%$ DFIG and $40 \%$ synchronous generator, for the same fault is shown in Fig. 10. The synchronous generator supplies more reactive power and thus provides better performances in contrast to DFIG to recover post-fault voltage. In some countries, the grid codes are so rigid, that the DFIGs must be combined with STATCOMs in order to achieve a similar behavior as the one of synchronous generators. In these cases, the wind generation can be considered as equal to a conventional generation.

\section{H. Effects of large scale fixed speed wind turbines (FSWTs) integration}

Grid-connected wind turbine generation system consists of both mechanical system and electrical system which is then connected to the distribution system to form a part of the existing utility network. The analyses carried in this paper have shown that as an interconnected power system, stability is likely to be affected by various factors contributed by the constituent distribution system and also by windmill mechanical and electrical properties.

Dominant mode and participation factors are determined for the growing level of FSIGs replacing the synchronous generators to analyse the above mentioned case. Five wind farms are connected in five areas at buses 54, 51, 41, 42 and 18. Fig. 11 shows the monotonic (dominant) mode under different FSWT integration level. Fig. 12 shows the damping and frequency of the mechanical modes as a function of the shaft stiffness which are due to the angle dynamics of the system. The participation factors are calculated when $25 \%$ of total power are supplied from wind turbine. The participation factors related to the shaft stiffness and operating slip of the
TABLE I

PARTICIPATION FACTORS (PF)

\begin{tabular}{|c|c|c|c|c|c|}
\hline Mode & $s_{5}$ & $\gamma_{5}$ & $s_{3}$ & $s_{2}$ & $\gamma_{3}$ \\
\hline PF & 1 & 0.99608 & 0.50313 & 0.49316 & 0.45430 \\
\hline Mode & $s_{1}$ & $\gamma_{2}$ & $\gamma_{1}$ & $\gamma_{4}$ & $s_{4}$ \\
\hline PF & 0.44890 & 0.34433 & 0.33963 & 0.33502 & 0.30439 \\
\hline
\end{tabular}

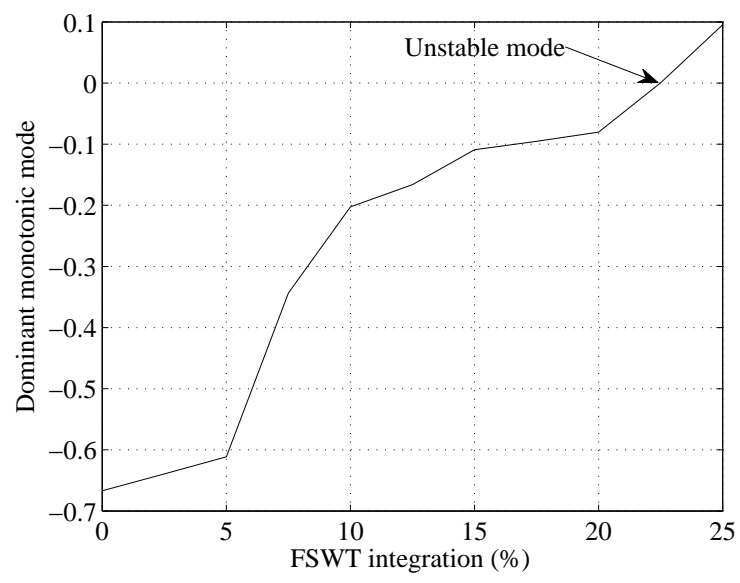

Fig. 11. Monotonic mode as a function of FSWT integration.

wind farms are shown in Table I as these two modes are mainly responsible for instability within the systems.

It is essential that wind generators have the fault ride through capability. If this is not enforced, the generators trip at based on a certain undervoltage criteria (e.g. 80\%). That means that in case of a fault, many units trip and that there is a great imbalance in the system. If this amount exceeds the primary control reserve, the system can collapse. The scenario is analyzed by replacing $G_{3}$ with a wind farm. Fig. 13 shows the voltage at bus 3 having a wind farm (i) with lowvoltage-ride-through LVRT capability, and (ii) without LVRT capability. From Fig. 13, it is clear that wind farm without LVRT capability may cause instability, which as also visible from Fig. 14 which shows the angle response for a three-phase

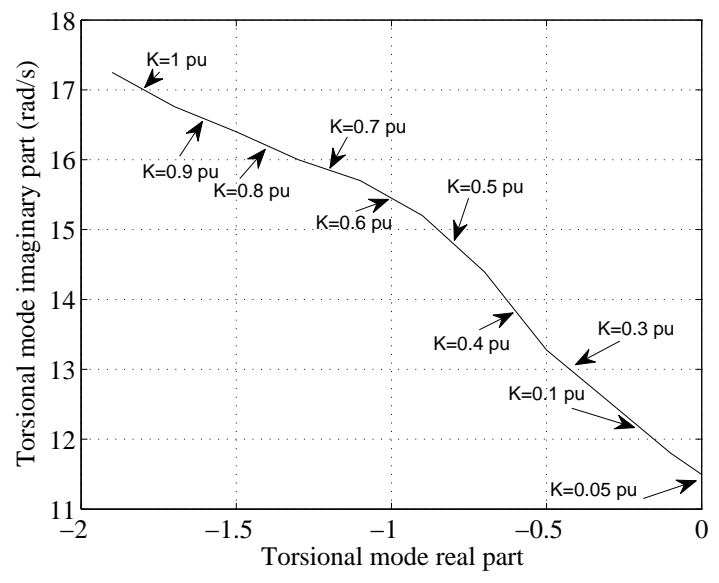

Fig. 12. Mechanical mode as a function of the shaft stiffness. 


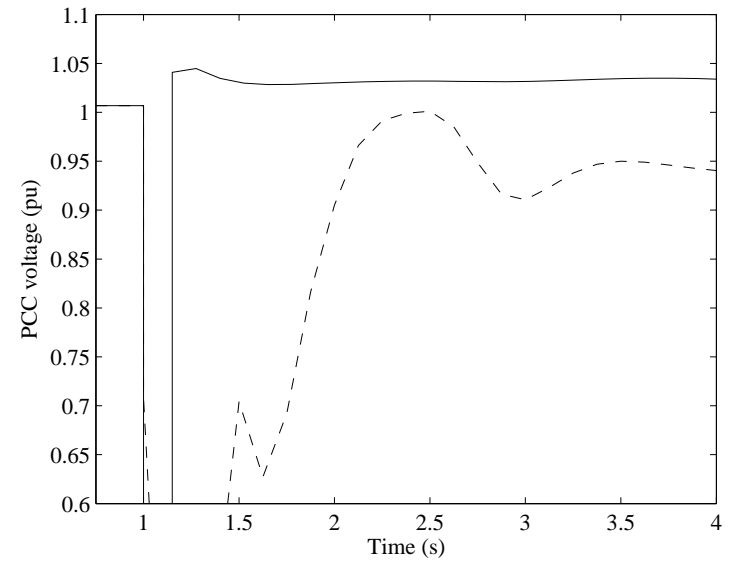

Fig. 13. PCC voltage for a three phase fault on the middle of line 60-61.

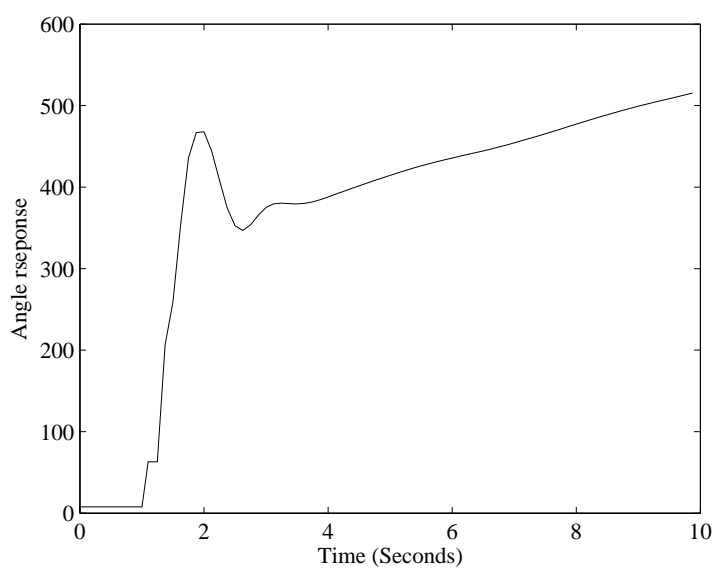

Fig. 14. Angle response for a three phase fault on the middle of line 60-61.

fault. In order to obtain an optimal integration of wind energy in the system, the large wind farms must be able to withstand network disturbances.

\section{Integration of overcompensated fixed-speed wind generators using STATCOM}

In the case of renewable energy, FACTS devices are especially advantageous when integrated with wind generators. As wind farms become a larger part of the total generation and as the penetration levels increase, issues related to integration such as transients, stability, and voltage control are becoming increasingly important. For wind generation applications, FACTS can be implemented for voltage control in the form of the shunt-connected SVC or STATCOM configurations.

The FSWTs and STATCOMs are integrated into the system repeatedly to find a certain level at which the system becomes unstable. The upper limit for a certain amount of compensations (STATCOM and shunt capacitor) is shown in Table II. It was found that 100 MVA STATCOM with 500 MVAr capacitor is required to integrate $24.5 \%$ FSWTs in different areas of the test system. For identifying the nature of instability during transients with upper limit, the method of
TABLE II

FSWT INTEGRATION AND STATCOM

\begin{tabular}{|c|c|c|c|c|c|}
\hline FSWT (MW) & 4500 & 6300 & 7325 & 8120 & 8600 \\
\hline STATCOM (MVAr) & 100 & 200 & 300 & 400 & 500 \\
\hline Capacitor (MVAr) & 500 & 1000 & 1500 & 2000 & 2500 \\
\hline
\end{tabular}

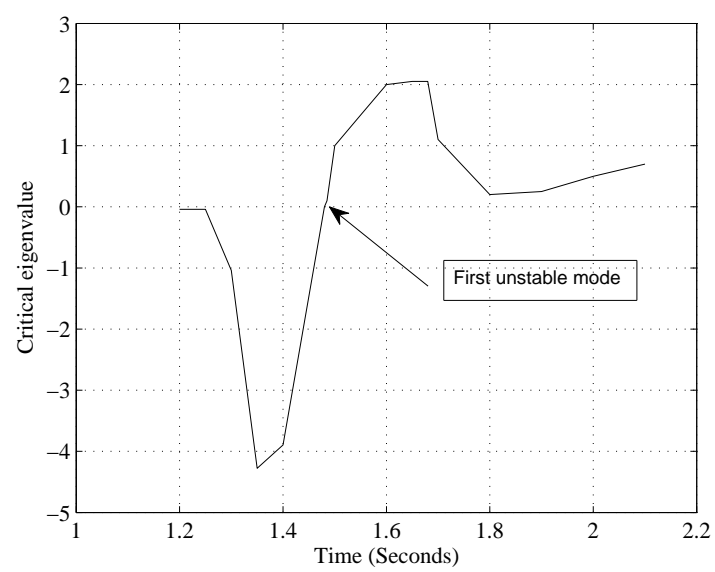

Fig. 15. Evolution of the critical eigenvalue in the unstable case.

eigenvalue tracking was used [26]. In this method, the system is repeatedly linearized at selected time instants during the simulation and the system eigenvalues are computed at each snapshot. With a fixed compensation level, the system becomes unstable after integration of certain level of FSWTs. Online linearization and eigenvalue tracking show that after fault clearing the monotonic mode shown in Fig. 15 correlated to generator slip and mechanical states is the first to be unstable.

\section{CONCLUSiOns}

In this paper, the impact of high compensation and large scale wind power integration on power system dynamic performance has been investigated. Modal analysis, participation factors, eigenvalue tracking and dynamic simulations have been used to analyze the nature of system behavior under large scale wind turbine and FACTS device integrations. Due to local, uncoordinated control strategies used in many power systems, destabilizing interactions among FACTS controls are possible. High compensation reduces the security limit under certain operating conditions. The modes related to operating slip and shaft stiffness are most critical and they may limit the large scale integration of wind generation.

\section{REFERENCES}

[1] P. M. Anderson and A. A. Fouad, Power System Control and Stability. New York: Wiley, John \& Sons, 2002.

[2] W. Qiao, R. G. Harley, and G. K. Encephalopathy, "Effects of FACTS devices on a power system which includes a large wind farm," in IEEE PES Power Systems Conference and Exhibition, June 2006, pp. 20702076.

[3] T. Ackermann and L. Soder, "An overview of wind energy-status 2002," Renewable and Sustainable Energy Reviews, Elsevier, vol. 6, pp. 67128, 2002. 
[4] M. R. Rathi and N. Mohan, "A novel robust low voltage and fault ride through for wind turbine application operating in weak grids," in 31st Annual Conference of IEEE Industrial Electronics Society, vol. 1, November 2005, pp. 2481-2486.

[5] M. P. Palsson, T. Toftevaag, K. Uhlen, and J. O. G. Tande, "Large-scale wind power integration and voltage stability limits in regional networks," in IEEE Power Engineering Society Summer Meeting, vol. 2, July 2002, pp. 762-769.

[6] M. J. Hossain, H. R. Pota, V. Ugrinovskii, and R. A. Ramos, "Robust STATCOM control for the enhancement of fault ride-through capability of fixed-speed wind generators," in IEEE Multi-Conference on Systems and Control, July 2009, pp. 1505-1510.

[7] J. Slootweg and W. Kling, "The impact of large scale wind power generation on power system oscillations," Electric Power Systems Research, Elsevier, vol. 67, pp. 9-20, 2003.

[8] J. Hagstrm, I. Norheim, and K. Uhlen, "Large-scale wind power integration in Norway and impact on damping in the Nordic grid," Wind Energy, Wiley Interscience, vol. 8, pp. 375-384, 2005.

[9] M. P. Palsson, T. Toftevaag, K. Uhlen, and J. O. G. Tande, "Large-scale wind power integration and voltage stability limits in regional networks," in IEEE Power Engineering Society Summer Meeting, vol. 2, July 2002, pp. 762-769.

[10] M. J. Hossain, H. R. Pota, and V. Ugrinovskii, "Short and long-term dynamic voltage instability,' in 17th IFAC World Congress ( IFAC'08), Seoul, Korea, May 2008, pp. 9392-9397.

[11] M. J. Hossain, H. R. Pota, V. Ugrinovskii, and R. A. Ramos, "Excitation control for large disturbances in power systems with dynamic loads," in IEEE Power and Energy Society General Meeting, July 2009, pp. 1-8.

[12] J. Enslin, J. Knijp, C. Jansen, and P. Bauer, "Integrated approach to network stability and wind energy technology for on-shore and offshore applications," in $24^{\text {th }}$ International Conference for Power Electronics, Intelligent Motion and Power Quality, Nuremberg, Germany, May 2003, pp. 1-8.

[13] L. Shi, S. Dai, Y. Ni, L. Yao, and M. Bazargan, "Transient stability of power systems with high penetration of DFIG based wind farms," in IEEE Power and Energy Society General Meeting, July 2009, pp. 1-6.

[14] A. D. Hansen and G. Michalke, "Fault ride-through capability of DFIG wind turbines," Renewable Energy, Elsevier, vol. 32, pp. 1594-1610, 2007.

[15] J. C. Smith, M. R. Milligan, E. A. DeMeo, and B. Parsons, "Utility wind integration and operating impact state of the art," IEEE Trans. on Power Systems, vol. 22, no. 3, pp. 900-908, 2007.

[16] V. Akhmatova and H. Knudsenb, "Large penetration of wind and dispersed generation into Danish power grid," Electric Power Systems Research, Elsevier, vol. 77, no. 9, 2007.

[17] R. Piwko, N. Miller, J. Sanchez-Gasca, X. Yuan, R. Dai, and J. Lyons, "Integrating large wind farms into weak power grids with long transmission lines," in IEEE/PES Transmission and Distribution Conference \& Exhibition: Asia and Pacific Dalian, China, 2005, pp. 1-7.

[18] P. Kundur, Power System Stability and Control. New York: McGrawHill, 1994.

[19] T. Ackermann, Wind power in power systems. England: John Wiley and Sons, Ltd, 2005.

[20] E. S. Abdin and W. Xu, "Control design and dynamic performance analysis of a wind turbine-induction generator unit," IEEE Trans. on Energy Conversion, vol. 15, no. 1, pp. 91-96, 2000.

[21] K. Nandigam and B. H. Chowdhury, "Power flow and stability models for induction generators used in wind turbines," in Power Engineering Society General Meeting, 2004, IEEE, vol. 2, June 2004, pp. 2012-2016.

[22] B. Pal and B. Chaudhuri, Robust Control in Power Systems. USA: Springer, 2005.

[23] IEEE Task Force, "Load representation for dynamic performance analysis," IEEE Trans. on Power System, vol. 8, no. 1, pp. 472-482, 1993.

[24] J. G. Slootweg, S. W. H. de Haan, H. Polinder, and W. L. Kling, "General model for representing variable speed wind turbines in power system dynamics simulations," IEEE Trans. on Power Systems, vol. 18, no. 1, pp. 144-151, 2003.

[25] T. V. Custem and C. D. Vournas, Voltage stability of the electric power systems. Norwell: Kluwer Acdemic, 1998.

[26] E. G. Potamianakis and C. D. Vournas, "Short-term voltage instability: effects on synchronous and induction machines," IEEE Trans. on Power Systems, vol. 21, no. 2, pp. 791-798, 2006. 